\title{
VULNERABILIDADE ÀS INUNDAÇÕES EM TERESINA, PIAUÍ E AÇÕES MITIGADORAS DO PODER PÚBLICO
}

\author{
Sammya Vanessa Vieira Chaves ${ }^{1}$ \\ Antônio Carlos Tavares ${ }^{2}$ \\ Carlos Sait Pereira de Andrade ${ }^{3}$
}

\section{Resumo}

No Brasil, as inundações são o tipo de desastre mais comum e recorrente, provocando graves transtornos nos centros urbanos. Em Teresina, Piauí, as inundações são os mais recorrentes. Pretendeu-se com essa pesquisa, traçar o perfil socioeconômico da população vulnerável às inundações e analisar o papel do poder públicofrente ao evento materializado.Para tanto, foram aplicados questionários nas áreas da cidade consideradas pela Companhia de Pesquisa de Recursos Minerais (CPRM) como vulneráveis às inundações. Concluiu-se que a privação econômica e a baixa escolaridade são condições predominantes entre os vulneráveis e o poder público mais atuante é a prefeitura municipal com ações incipientes e insatisfatórias, paliativas e emergenciais.

Palavras-Chave: Inundação, vulnerabilidade, Teresina, poder público.

\section{VULNERABILITY TO FLOODS AT TERESINA, PIAUÍ, AND MITIGATIVE ACTIONS OF PUBLIC POWER}

\begin{abstract}
In Brazil, floods are the most common and recurrent kind of disaster, causing serious disorders in urban centers. The same applies to Teresina-PI. We intended with this research to draw the socioeconomic profile of the population that are more vulnerable to floods and to analyze the role of the government when facing the consummate event. In order to do so, questionnaires were applied in the areas of the city considered the most vulnerable to floods by the Company of Research in Mineral Resources (CPRM). We can conclude that economic deprivation and low scholarity are the predominant conditions between the vulnerable people and that the Municipal Government was the most active among them, even though with incipient and unsatisfactory actions and palliative and emergency services.
\end{abstract}

Key words: Inundation, vulnerability, Teresina, public government.

\footnotetext{
${ }^{1}$ Doutora em Geografia pelo Programa de Pós-Graduação em Geografia da Universidade Estadual Paulista "Júlio de Mesquita Filho" (UNESP/Rio Claro) e docente do Instituto Federal de Educação, Ciência e Tecnologia do Piauí (IFPI). E-mail: sammyachaves@ifpi.edu.br.

2 Professor livre docente em Geografia pela Universidade Estadual Paulista "Júlio de Mesquita Filho" (UNESP/Rio Claro). E-mail: atavares@rc.unesp.br.

3 Professor adjunto do Departamento de Geografia da Universidade Federal do Piauí. E-mail: carlossait@ufpi.edu.br.
}

Sociedade e Território - Natal. Vol. 29, N. 2, p. 175-197, Jul./Dez. de 2017. 


\section{VULNERABILIDAD A LAS INUNDACIONES EN TERESINA, PIAUÍ, Y ACCIONES MITIGADORAS DE EL PODER PUBLICO}

\section{Resumen}

En Brasil, las inundaciones son el tipo de desastre más común y recurrente, provocando graves trastornos en los centros urbanos. El mismo se aplica a Teresina-PI. Se pretendiócon esa investigación, trazar el perfil socioeconómico de la población vulnerable a las inundaciones, asícomo analizar el papel del poder público frente al evento materializado. Para eso, se aplicaron cuestionarios en las áreas de la ciudad consideradas por la Compañía de Investigación de Recursos Minerales (CPRM) como vulnerables a las inundaciones.Se concluyóque la privación económica y la baja escolaridad son condiciones predominantes entre los vulnerables y el poder público más actuante es laprefecturamunicipal con acciones incipientes e insatisfactorias, paliativas y de emergencia.

Palabras-clave: Inundación, vulnerabilidad, Teresina, poder público.

\section{INTRODUÇÃO}

A humanidade, desde tempos remotos, convive com desastres de ordem natural e busca explicações para sua ocorrência. Terremotos, furacões, tsunamis, inundações, deslizamentos de terras, eram tidos como fenômenos sobrenaturais, castigos divinos ou oriundos da própria natureza, ideias que permearam e ainda permeiam muitas concepções (ROMERO e MASKREY,1993). Tais interpretações fatalistas, demonstravam a impotência do homem diante da força da natureza e culminavamnuma espécie de conformismo e imobilidade ante a ocorrência dos desastres naturais.

Segundo a Estratégia Internacional das Nações Unidas para a Redução dos Desastres (UNISDR, 2009), um desastre provoca grave perturbação do funcionamento de uma comunidade ou sociedade, grande número de mortes, perdas materiais, econômicas e ambientais, que excedem a capacidade da sociedade afetada em lidar com as consequências do evento com seus próprios recursos. O EM-DAT (EmergencyEventsDatabase) corrobora este conceito ao acrescentar a necessidade de assistência em nível nacional ou internacional. Além de cumprir pelo menos um dos seguintes critérios: 10 ou mais mortes; 10 ou mais pessoas afetadas; declaração de estado de emergência e pedido de auxílio internacional.

Um desastre natural, via de regra é precedido pela ocorrência de um fenômeno natural, vez que diversos fenômenos fazem parte da geodinâmica terrestre e da estruturação da paisagem. Se gerarem danos e prejuízos de difícil superação para a comunidade afetada, serão considerados desastres, se não, serão considerados apenas eventos naturais (MARCELINO, 
2007). Os eventos classificados como desastres naturais estão relacionados com a dinâmica interna e externa da Terra, sendo os internos resultantes dos movimentos das placas tectônicas e os externos reflexos dos agentes atmosféricos (KOBIYAMA et al., 2006).

Em se tratando da tomada de atitudes ante os desastres naturais, dava-se, anteriormente, ênfase a atividades de respostas e ajudas humanitárias pós-desastres e pouca atenção às estratégias de prevenção. A partir da década de 1990, por meio da avaliação dos riscos e da vulnerabilidade da população, os esforços se voltaram para a redução dos efeitos adversos dos desastres (PNUMA, 2004).

O conhecimento dos dados específicos acerca dos desastres, com ênfase na localização da ocorrência, é importante para compreender como e porque um fenômeno natural pode se transformar em um desastre (PEDUZZI et al. 2005). Nos países em desenvolvimento a população mais pobre tende a ocupar áreas afetadas por sismos, vulcões, inundações, etc. ou seja, áreas mais propensas à ocorrência de um fenômeno natural. Nesses países o desenvolvimento, econômico, social, político e cultural apresenta sérias deficiências, o que dificulta a recuperação pós-desastres, aumenta o número de vítimas e as perdas econômicas (ALCÂNTARA-AYALA, 2002).

Inexiste no Brasil uma tendência natural para fenômenos tectônicos de grande magnitude - terremotos, tsunamis e vulcões - devido à estabilidade da sua crosta, contudo há frequentes registros de desastres oriundos de variabilidades climáticas e instabilidades atmosféricas, como as inundações, secas e estiagens e os movimentos de massa (MARCELINO, 2008; MAFRA, MAZZOLA, 2007). A maioria desses desastres se relaciona aos eventos naturais extremos associados aos processos de degradação ambiental e à vulnerabilidade agravada pela ação humana (SOBRAL et al., 2010; MAFRA, MAZZOLA, 2007), tais como a ocupação de áreas inadequadas ea degradação ambiental- desmatamento das matas ciliares e áreas de encostas e impermeabilização excessiva, dentre outras.

Pretende-se com essa pesquisa, discutir sobre desastres naturais do Brasil, enfatizando a situação do município de Teresina, Estado do Piauí, que registra com frequência, episódios de inundaçãoe demonstraras ações do poder público diante da materialização das inundações nas diversas zonas da cidade.

Os procedimentos metodológicos para a execução da pesquisa perpassam pela caracterização do sítio urbano de Teresina, análise das precipitações em anos de chuvas intensas que culminaram com as inundações e a descrição das ações do poder público diante da materialização das inundações, segundo os moradores das áreas mais vulneráveis.

Sociedade e Território - Natal. Vol. 29, N. 2, p. 175-197, Jul./Dez. de 2017. 
As informações que consubstanciaram a análise da dinâmica climática foram baseadas em documentos públicos elaborados por órgãos atrelados ao município e ao Estado e a descrição das ações do poder púbicos foram retiradas de uma pesquisa direta realizada com aproximadamente 400 chefes de família, moradores das áreas consideradas como vulneráveis às inundações em Teresina, de acordo com a Companhia de Pesquisa de Recursos Naturais/Serviço Geológico do Brasil (CPRM/SGB) no ano de 2012.

\section{DESASTRES NATURAIS E VULNERABILIDADE}

Estudos indicam que, nas últimas décadas, os países mais propensos à ocorrência de desastres naturais são os de baixa renda, baseados em economias simples, que apresentam um ritmo mais lento de desenvolvimento econômico (UNITED NATIONS DEVELOPMENT PROGRAMME, 2001).

Sobre a ocorrência dos desastres naturais e o grau de desenvolvimento dos países afetados, o PNUMA (2004, p. 292) defende que:

Em casos de desastre, os países menos desenvolvidos, com uma diversidade
econômica limitada e infraestrutura precária, não somente estão obrigados a
depender em grande parte da ajuda internacional, mas suas economias também
precisam de mais tempo para recuperar-se. Nas economias desenvolvidas, os
governos, as comunidades e as pessoas têm uma maior capacidade de lidar com
desastres, as perdas econômicas são absorvidas até certo ponto por uma economia
diversificada, e a maior parte dos bens está assegurada.

Alguns índices demonstram a vulnerabilidade dos países em desenvolvimento aos desastres naturais: entre 1990 e 2002, mais da metade dos desastres ocorreram em países de índices médios de desenvolvimento humano, contudo, dois terços das vítimas eram oriundas de países com baixos níveis de desenvolvimento humano e apenas $2 \%$ eram de países altamente desenvolvidos.Isso reflete a diferença quanto ao efeito do impacto: em média, 22,5 pessoas morrempor desastre registrado em países altamente desenvolvidos, nos países de desenvolvimento humano médio há, em média, 145 mortes e 1.052 em países de baixo desenvolvimento humano (PNUMA, 2004).

A vulnerabilidade física está presente nesses países, uma vez que as áreas mais propensas aos desastres se encontram ocupadas e a vulnerabilidade humana, concebida como a capacidade da população em lidar com o evento, é deficiente quando comparada com a dos países desenvolvidos, dada a fragilidade do seu aporte social, econômico e cultural (PEDUZZI et al., 2005).Nos países de baixos índices de desenvolvimento humano convergem 
as vulnerabilidades física e humana ante aos desastres naturais (ALCÂNTARA-AYALA, 2002).

A respeito da correlação acerca da severidade dos desastres e vulnerabilidades física e humana, Sobral et al (2010, p.390) argumentam que:

(...) a vulnerabilidade humana, resultante da pobreza e da desigualdade social,
potencializa os riscos. Essa vulnerabilidade está relacionada à capacidade da
comunidade suportar e responder adequadamente a determinado evento. Ou seja, a
magnitude do evento desencadeador representa um fator importante na ocorrência
do desastre, mas o grau de vulnerabilidade da área geográfica e/ou da comunidade
afetada é um dos fatores preponderantes para a intensificação de suas consequências.

Um desastre também pode ser visto como a combinação de um evento natural em um receptor vulnerável, pouco capaz de lidar com a adversidade gerada. Nessa perspectiva, a vulnerabilidade pode se referir às condições dos ecossistemas, mas pode também considerar as condições socioeconômicas da população atingida. Um desastre, embora precedido por um evento natural, não se dissocia dos aspectos sociais resultantes da combinação de ameaças, capacidade de resposta e condições de vulnerabilidade socioambiental (SOBRAL, 2010).

Os índices registrados pelo EM-DAT em 2012 comprovam os efeitos adversos dos desastres quando ocorrem em áreas de vulnerabilidade física e humana. Dos dez países que registraram a maior mortalidade por desastres naturais, seis são considerados de baixa renda. Nesses países ocorreram 68,2\% das mortes registradas. Paquistão, Índia, Nigéria, Irã, Peru e Afeganistão, juntos, registraram mais de 2.500 óbitos (GUHA-SAPIR, 2013).

Os desastres associados ao clima são, sem dúvidas, os mais recorrentes e, certamente, os que mais ameaçam a segurança humana. Entre 2000 e 2006, 2.163 desastres relacionados ao clima foram reportados aos bancos de dados do EM-DAT, matando mais de 290 mil pessoas, afetando mais de 1,5 bilhão de pessoas e gerando mais de 422 bilhões de dólares em danos nos Estados Unidos (ADIKARI, YOSHITANI, 2009). As perdas econômicas só refletem a concentração das construções humanas em áreas sujeitas à ocorrência desses desastres.

O aumento no número de vitimados por desastres naturais no Brasil está diretamente atrelado ao processo de urbanização e falta de um planejamento adequado, com o intuito de coibir a ocupação de áreas suscetíveis à ocorrência de desastres naturais. Parcelas da população que não possuem condições econômicas para adquirir moradias em áreas urbanas seguras são impelidas a ocupar áreas inadequadas, tais como as várzeas, que são inundáveis, 
ou áreas de encostas íngremes, onde assentamentos precários promovem cortes em terrenos instáveis e contribuem para ocorrência dos movimentos de massa.

Desse modo, áreas de elevada declividade e margens de rios foram ocupadas nas cidades brasileiras, resultando em parcelas urbanas de extrema vulnerabilidade a deslizamentos de encostas, inundações e enxurradas (BERTONE e MARINHO, 2013). E é sob essa égide que os estudos de vulnerabilidade se afirmam. $\mathrm{Na}$ mensuração dos riscos enfrentados pela população urbana e sua capacidade de resposta ou adaptação diante da ocorrência de um desastre.

Alguns fatores intrínsecos à condição geográfica do país podem contribuir para a ocorrência dos desastres naturais e se configurar numa combinação perigosa. Em muitos locais as características do relevo favorecem a ocorrência de processos geomecânicos e hidrológicos que, diante da ocupação destas áreas, tendem a aumentar a vulnerabilidade humana. Somados a atuação de sistemas atmosféricos distintos ao longo do ano, geradores de chuvas intensas e concentradas, de tornados, granizo, de secas e estiagens prolongadas. (BRASIL, 2012a).

São nas cidades queas perdas por desastres naturais têm grande proporção. A alta densidade populacional em meio urbano, intensifica fluxos de toda ordem e problemas inerentes à relação homem e natureza, consubstanciados pela expansão de modo desordenado, comprometem a qualidade de vida de boa parte dos seus residentes, principalmente pela ocupação inadequada de áreas de risco de recorrentes desastrese corroboram para os prejuízos ocorridos com a materialização de um desastre (MENDONÇA, 2010).

Estudos acerca da vulnerabilidade em áreas urbanas vêm sendo, nos últimos anos, valioso instrumento utilizado por diversos estudiosos no sentido de apontar as áreas das cidades em que a população é suscetível a qualquer desastre que comprometa a sua qualidade de vida. Estes enfoques crescem dentro das mais diversas ciências e vêm ganhando importância no seio da gestão urbana, uma vez que podem subsidiar políticas públicas que minimizem os problemas de parcelas significativas dos citadinos que estão suscetíveis a deslizamentos, inundações, enxurradas, dentre outros desastres. Sobre vulnerabilidade Cutter (2011, pag. 59) afirma que:

A ciência da vulnerabilidade consiste na integração multidisciplinar das ciências sociais, das ciências naturais e da engenharia na compreensão das circunstâncias que colocam as populações e os locais em risco devido aos perigos, e dos fatores que aumentam ou reduzem a capacidade de resposta e de recuperação das populações, dos sistemas físicos ou das infraestruturas em relação a ameaças ambientais. 
A autora defende que a vulnerabilidade tem origem no potencial para a perda e procura analisar os fatores que podem influenciar as capacidades locais no que tange à preparação e resposta para a recuperação de um desastre, examinando de forma comparativa os vários padrões daí resultantes, pretendendo, dessa forma, apontar as áreas mais e menos vulneráveis ante a ocorrência de um desastre. Nesse caso, são as vulnerabilidades de pessoas e não dos recursos naturais que serão o centro de atenção (CUTTER, 2011; CUNHA, 2004).

Estudos da vulnerabilidade aos desastres mais recorrentes no Brasil, a saber, inundações e deslizamentos, têm sido utilizados como forma de minimizar os efeitos da sua materialização. Mendonça (2004), afirma que a vulnerabilidade envolve parcelas da sociedade que se encontram expostas a problemas ligados ao ambiente (risco ambiental); à condição de pobreza; à gestão urbana e à forma organizacional da cidade. Corresponde à exposição de parte da sociedade à ocorrência de um evento e ao modo de como ela reage diante de sua materialização.

\section{TERESINA: SÍTIO URBANO E AS INUNDAÇÕES}

Teresina, Piauí, está localizada no Meio-Norte brasileiro, na mesorregião centro-norte do Estado (figura 1), à margem direita do médio curso do rio Parnaíba, a 366 quilômetros do litoral. É conurbada com o município maranhense de Timon, a oeste, possui uma altitude média de $74,4 \mathrm{~m}$ e está situada entre $05^{\circ} 05^{\prime} 21^{\prime \prime}$ de latitude sul e $42^{\circ} 48^{\prime} 07^{\prime \prime}$ de longitude oeste, no baixo interflúvio que se alonga junto à confluência dos rios Parnaíba e Poti (MOREIRA, 1972; TERESINA, 2013).

Fundada no século XIX (1852) com a função de abrigar a capital do estado, sendo o local escolhido o médio curso do rio Parnaíba, à época, o principal eixo de circulação e exteriorização do estado, com condições potenciais e embrionárias para o seu desenvolvimento (MOREIRA, 1972; REIS FILHO, 2012). O município tem como caracterização principal o fato de estar assentado num interflúvio entre os rios Parnaíba e Poti, o que engendrou a ocupação das margens de ambos. Na figura 2 é possível ver a localização dos dois rios e os bairros existentes nas suas proximidades.

Sociedade e Território - Natal. Vol. 29, N. 2, p. 175-197, Jul./Dez. de 2017. 
Figura 1: Mapa de Localização de Teresina

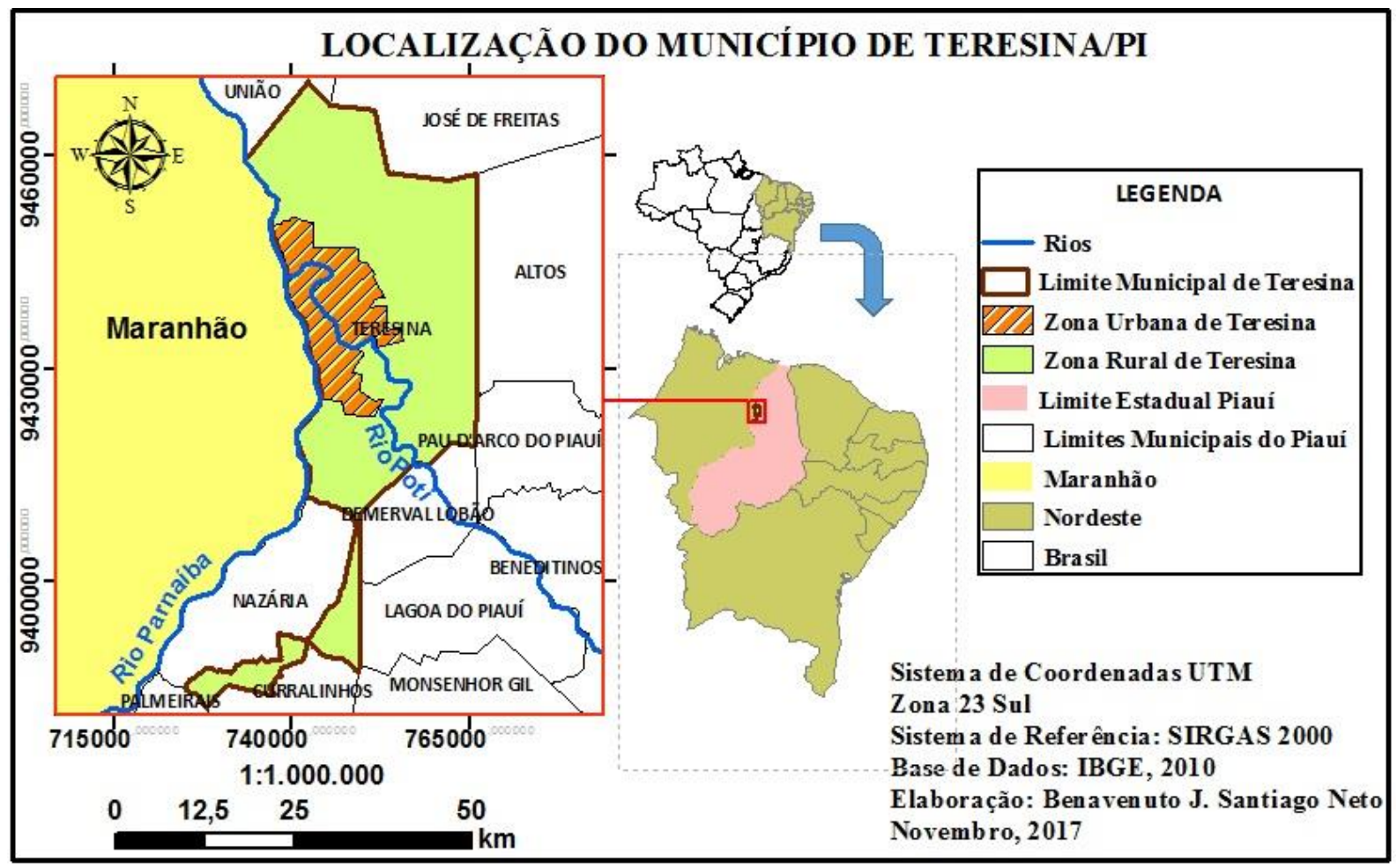

Organizado por: CHAVES, 2014. Elaborado por SANTIAGO NETO 2014.

As primeiras edificações da capital se localizaram em terrenos situados entre 60 a 70m de altitude, próximos ao rio Parnaíba, caracterizados por não apresentarem descontinuidades topográficas e formarem o interflúvio denominado de Chapada do Corisco, de 80 a 90m de altitude, aproximadamente a $30 \mathrm{~m}$ acima do leito fluvial. Os aclives que levam ao interflúvio não configuraram obstáculos ao crescimento da cidade em direção à chapada, considerada área mais salubre do que as ribeirinhas, geralmente inundáveis. Com perfil alongado de sul para norte, o interflúvio, de topografia suave, favoreceu a expansão inicial da malha urbana de Teresina nestas direções (MOREIRA, 1972). Tais informações demonstram a estreita relação dos teresinenses com os rios Parnaíba e Poti. 
Figura 2: Mapa do relevo e da drenagem da cidade de Teresina, Piauí

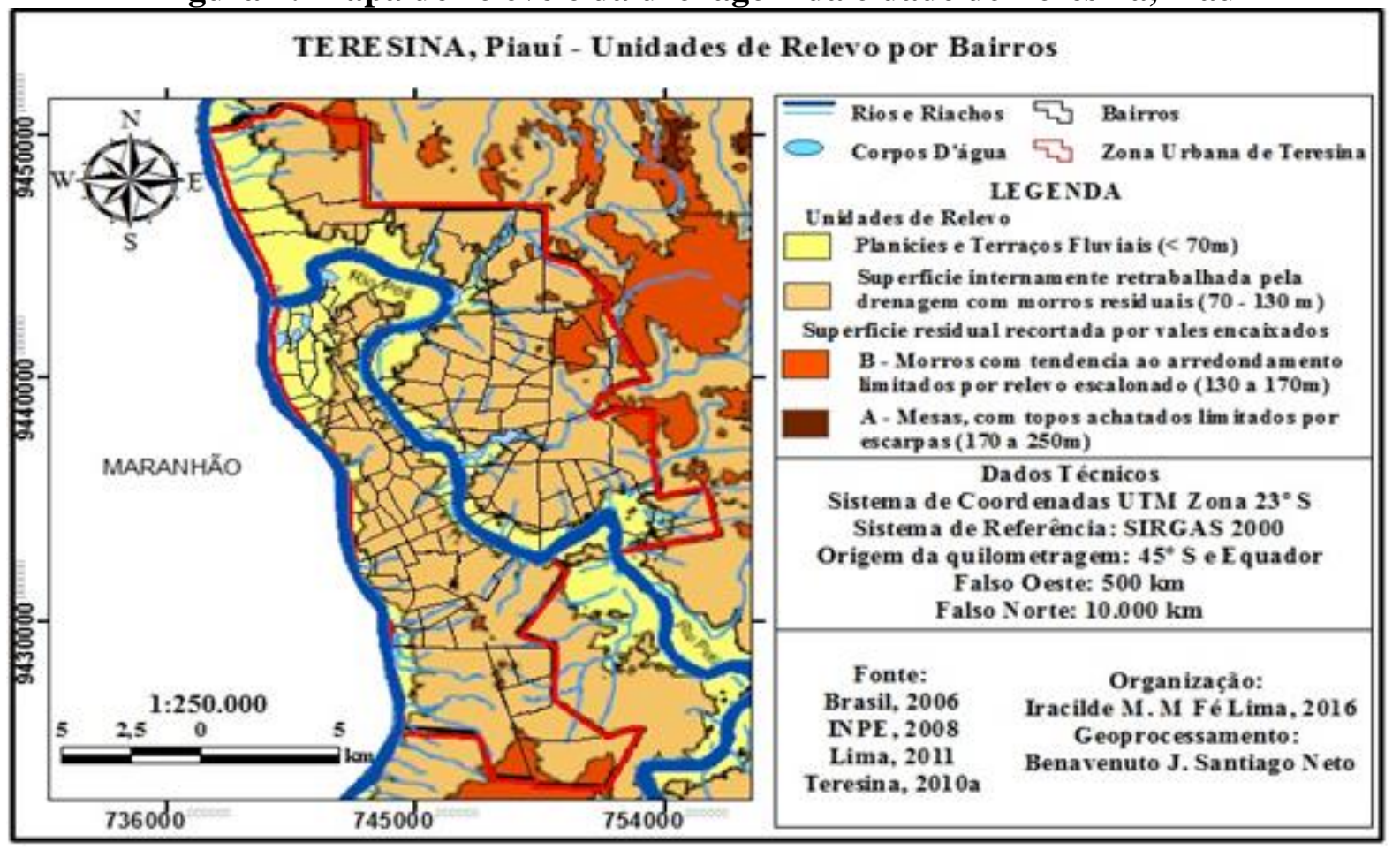

Fonte: LIMA, 2016.

Os rios Parnaíba e Poti possuem numerosos afluentes de pequena extensão, em sua maioria com nascentes no próprio município, muitos dos quais canalizados. Ambos são dotados de lagoas marginais, que se concentram, sobretudo, na área norte da cidade, nas imediações da foz do Poti. A zona norte abriga 34 lagoas, algumas antrópicas, com profundidades e dimensões variadas. Muitas das lagoas foram aterradas para a expansão da cidade, aumentando o problema das inundações (TERESINA, 2002; 2010; LIMA, 2011).

Conforme a Prefeitura Municipal de Teresina, há 70 sub-bacias hidrográficas em toda a área urbana, das quais 16 drenam em direção à margem direita do Poti, 32 em direção à margem esquerda e 22 para o rio Parnaíba. Os terraços fluviais são mais extensos no Poti e menores no rio Parnaíba. Diante das inundações, os terraços, em alguns pontos da cidade, têm sido evitados para a ocupação e utilizados para cultivos de culturas intermitentes. No entanto, em determinadas áreas foram ocupados inadequadamente e são pontos recorrentes de inundações (TERESINA, 2002). As inundações ocorrem em algumas áreas, principalmente no período chuvoso, de dezembro a maio. As precipitações que ocorrem durante esse período são caracterizadas como de grande intensidade e acompanhadas por raios e trovoadas.

Há em Teresina uma grande heterogeneidade na ocupação do seu território, com áreas de vazios urbanos se contrapondo a áreas intensamente ocupadas, com variações no que tange à impermeabilização do terreno. Encontram-se em alguns bairros da cidade, grandes Sociedade e Território - Natal. Vol. 29, N. 2, p. 175-197, Jul./Dez. de 2017. 
extensões de jardins e pátios arborizados, denotando uma baixa impermeabilização relativa. Em outras áreas, apresentam-se grande quantidade de edificações, indicando elevada taxa de ocupação e, por conseguinte, alta impermeabilização.

A sua urbanização se deu de modo assimétrico e excludente, as áreas de melhor localização foram ocupadas pela população de classes média e alta, tendo a população de baixa renda que ocupar as zonas mais periféricas, muitas vezes em terrenos impróprios para habitação, contribuindo também para intensificação dos loteamentos clandestinos e espraiamento de vilas e favelas. A falta de planejamento urbano tem contribuído sobremaneira para o aumento do número de afetados por inundações. A expansão urbana desordenada, principalmente no que tange à ocupação das planícies fluviais dos rios Parnaíba e Poti, e o aumento populacional agravam o problema. Frequentemente a ocupação dessas áreas, aqui configuradas como áreas de riscos, é realizado por uma parte da população considerada de baixa renda, em assentamentos precários, impossibilitada de ocupar partes da cidade não inundáveis.

\section{A ocorrência das inundações em Teresina: história e recorrências}

Às margens do rio Poti, por volta de 1760, já se encontrava um aglomerado de casas habitadas por canoeiros, pescadores, plantadores de fumo e mandioca, constituindo o primeiro segmento urbano da Teresina, denominado de Vila do Poti. Já nessa época, a Vila padecia com inundações constantes e foi transferida para um local mais alto, com condições favoráveis à implantação da futura capital, a salvo das cheias dos rios e com possibilidade de se expandir (TERESINA, 1993). Nessa época, muitas casas foram destruídas e parte do comércio ficou alagada, uma vez que grande parte das residências e do comércio se aglutinavam nas proximidades do rio Parnaíba, conforme pode ser visto na figura 3 a seguir.

Isso demonstra que historicamenteessa população sofre com problemas decorrentes das cheias dos seus rios. Chaves (1998) discorre sobre como nasceu Teresina:

\footnotetext{
Mal situada a Vila do Poti em lugar insalubre e sujeita a inundação, nos invernos rigorosos anteriores a 1842 as águas do rio aumentaram seu volume, espalhando-se em torno da vila, deixaram-na completamente ilhada e, na velocidade da sua baixa, arrastaram consigo parte de suas casas, inutilizaram sua lavoura e causaram mil danos (...) (CHAVES, 1998, p. 163).
} 
Figura 3: Inundação de 1926. As águas do rio Parnaíba atingiram a antiga Companhia de Fiação e Tecidos localizada às margens do rio Parnaíba.

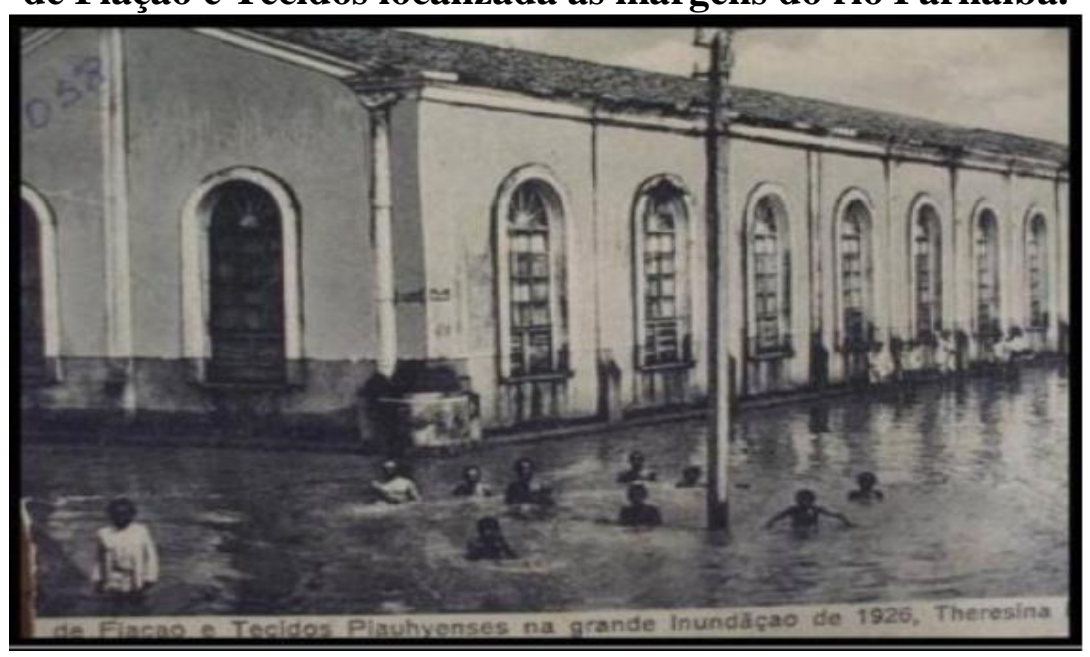

Fonte: Coutinho, 2014.

Nas últimas três décadas, as inundações dos anos de 1985, 2004, 2008 e 2009 foram as que mais se destacaram, com precipitações entre $1.500 \mathrm{~mm}$ e $2.600 \mathrm{~mm}$. Os prejuízos acarretados foram volumosos e praticamente todas as zonas da cidade foram atingidas (CHAVES, 2009). Em 1985, uma década após a construção do dique de proteção contra as inundações do rio Parnaíba, na zona norte da cidade, marca uma das mais devastadoras inundações, a água atingiu a Avenida Maranhão e outras ruas da área central da cidade (figura $4)$.

Figura 4: Avenida Maranhão, zona central da cidade, inundada com o transbordamento do rio Parnaíba em 1985.

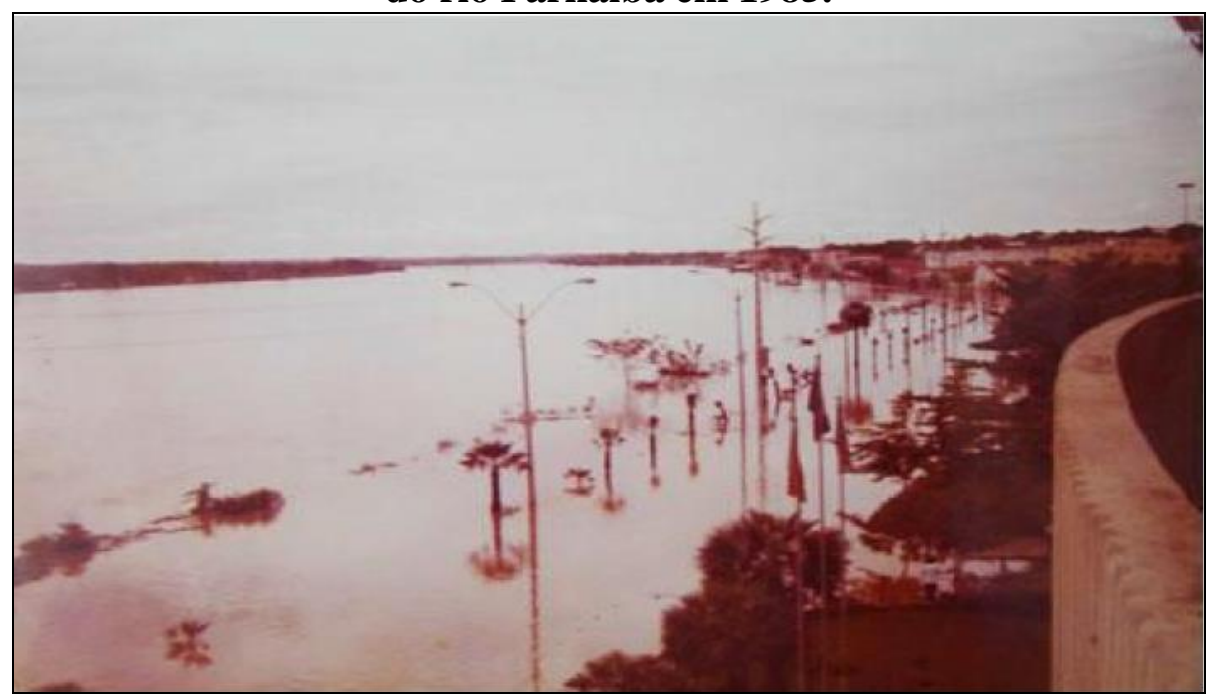

Fonte: Coutinho, 2014.

Sociedade e Território - Natal. Vol. 29, N. 2, p. 175-197, Jul./Dez. de 2017. 
Uma coincidência dos picos de vazão dos rios Poti e Parnaíba, provocou o transbordamento do rio Poti, numa posição não protegida pelo dique, inundando dezenas de bairros da capital. Os picos de vazão decorreram das intensas precipitações, com total anual de 2.568,5mm, um dos mais altos da história de Teresina. O poder público agiu retirando a população das áreas atingidas e alocando-as num loteamento mais ao norte, distante da ação dos rios, originando um dos bairros mais populosos da cidade, o Santa Maria da Codipi.

Em tempos recentes, as inundações ocorridas nos anos de 2004, 2008 e 2009 podem ser consideradas como as que mais castigaram os teresinenses. Nestes anos, a ação da ZCIT foi bastante intensa no hemisfério sul, fez as precipitações se estenderem até o mês de maio e culminarem com índices pluviométricos acima da média anual, que é de 1.335mm. Em 2004, 2008 e 2009, as chuvas foram de $1.646,2 \mathrm{~mm}, 1.714,9 \mathrm{~mm}$ e $2.028 \mathrm{~mm}$, respectivamente, conforme dados do Instituto Nacional de Meteorologia (INMET). A tabela um a seguir, mostra a precipitação anual, o número de dias de chuva, a pluviosidade de janeiro a maio e pessoas afetadas por inundações nos referidos anos.

Tabela 1: Panorama das condições de precipitação, dias de chuva, vazões dos rios e números de atingidos pelas inundações nos anos de 2004, 2008 e 2009.

\begin{tabular}{|c|c|c|c|c|}
\hline ANO & $\begin{array}{l}\text { PLUVIOSIDADE } \\
\text { ANUAL } \\
(\mathrm{mm})\end{array}$ & $\begin{array}{l}\text { DIAS DE } \\
\text { CHUVA* }\end{array}$ & $\begin{array}{c}\text { PLUVIOSIDADE } \\
\text { DURANTE O } \\
\text { PERÍODO } \\
\text { CHUVOSO** }(\mathrm{mm})\end{array}$ & $\begin{array}{l}\text { NÚMERO DE } \\
\text { ATINGIDOS*** }\end{array}$ \\
\hline 2004 & $1.646,2$ & 152 & $1.465,5$ & 3.000 \\
\hline 2008 & $1.714,9$ & 125 & $1.613,7$ & 3.500 \\
\hline 2009 & 2.028 & 151 & $1.658,1$ & 14.400 \\
\hline
\end{tabular}

FONTE: PIAUÍ, 2015; LIMA e FERNANDES, s/a; TERESINA, 2002b;

Notas: *Total de dias de chuva durante os 4 meses que correspondem ao período chuvoso.

** Total de precipitação registrado durante os 4 meses que correspondem ao período chuvoso.

*** Números aproximados.

É importante salientar que nos meses que correspondem ao período chuvoso, as precipitações foram elevadas. Por exemplo, em janeiro de 2004, ela foi de 511,8mm e em abril de 2008 e 2009, de 426,4mm e 420,0mm, respectivamente, valores bem superiores às médias, que são de 199,4mm e 277,4mm, respectivamente (LIMA e FERNANDES, s/a). Nestes meses se registraram os episódios mais graves de inundações em Teresina. Com a inundação de 2004, cerca de 3.000 famílias ficaram desabrigadas, principalmente as residentes em bairros da zona norte. As intensas e frequentes precipitações e a montante do rio Parnaíba e dos seus afluentes, fizeram o nível do rio ultrapassar a cota altimétrica local, Sociedade e Território - Natal. Vol. 29, N. 2, p. 175-197, Jul./Dez. de 2017. 
deixando grande parte da zona norte debaixo d'água (figura 5). É importante destacar que a zona norte é a que possui a mais baixa altitude, com $56 \mathrm{~m}$, sendo a média da capital, $72 \mathrm{~m}$ (TERESINA, 2002).

\section{Figura 5: Inundação ocorrida em 2004 em Teresina, resultante do transbordamento do rio Parnaíba, atingindo diversos bairros da capital, em especial, da zona norte.}

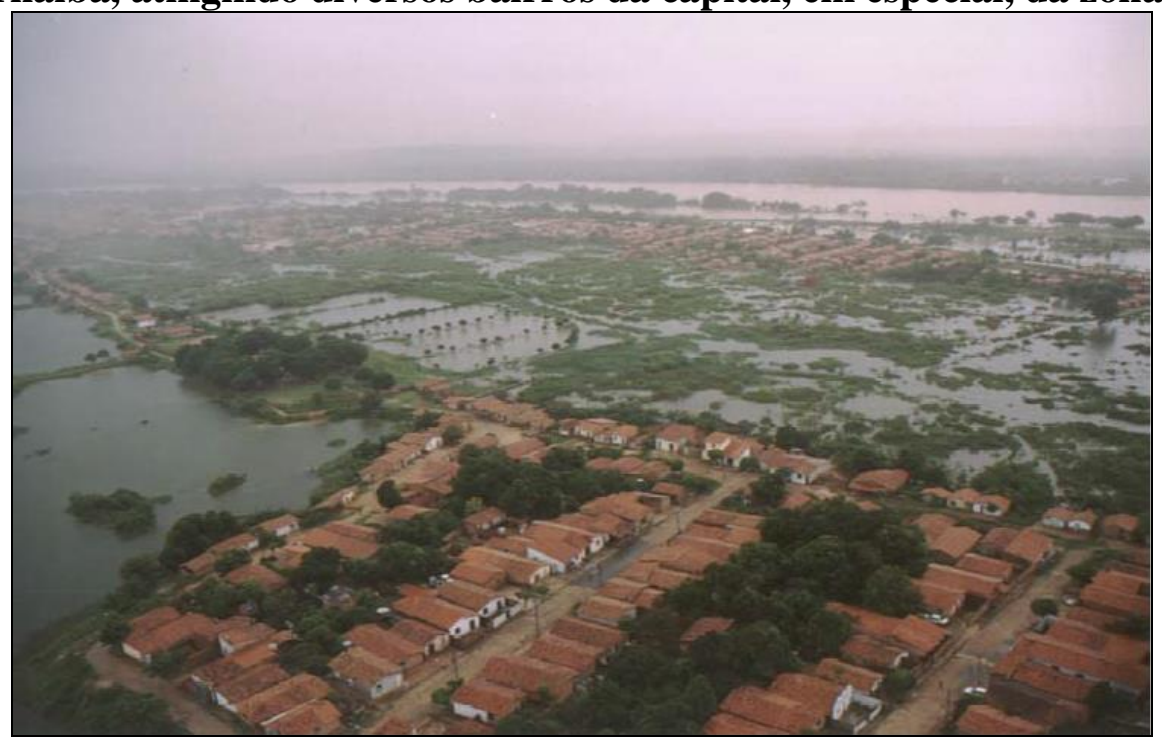

Fonte: Teresina, 2006.

Nos eventos ocorridos em 2008, o rio Poti foi o responsável pelas inundações em diversos pontos da cidade. O mesmo atingiu a sua segunda maior vazão da década, seu nível se elevou a quase $14 \mathrm{~m}$, ocupando o leito maior e inundando as áreas ocupadas pela população ribeirinha. Nesse ano foram desabrigadas cerca de 3.500 pessoas e um número considerável de famílias foram removidas das áreas de risco das zonas norte (265), sul (126), leste (29), sudeste (123) e zona rural (116).

Parte dos desabrigados e desalojados foram amparados pelo programa assistencialista da prefeitura "Família Acolhedora" ou foram abrigados em ginásios, escolas e igrejas espalhados pela cidade. Por conta desses fatores, foi decretado estado de calamidade pública pelo poder municipal (BARBOSA, 2008; COELHO, 2008). As precipitações acima da média histórica ocorridas em Teresina em 2008, de acordo com o Boletim de Informações Climáticas do CPTEC/INPE (2008), estão associadas principalmente à ação da ZCIT e à formação de cavados em médios e altos níveis.

O rio Poti apresentou em maio de 2009 uma vazão de $3.658 \mathrm{~m}^{3} / \mathrm{s}$ e uma cota máxima de 14,52m. De acordo com estudos feitos pela Companhia Hidrelétrica do São Francisco (CHESF), espera-se que o valor referente a essa vazão seja igualado ou superado apenas uma 
vez em um intervalo de 50 anos. Esta vazão é considerada a maior das últimas quatro décadas, superando, inclusive, a registrada em $1985\left(3.210 \mathrm{~m}^{3} / \mathrm{s}\right)$, em função das fortes chuvas caídas na nascente do Poti no estado do Ceará (SEMAR s/a). Informações da Defesa Civil confirmam que 14.397 famílias foram atingidas pelas inundações, das quais 4.000 ficaram desabrigadas e 10.000 desalojadas.

De acordo com estudos solicitados pela Prefeitura, a ocorrência de inundações está ligada ao assoreamento dos rios na capital, principalmente em alguns pontos do rio Poti, onde o escoamento das águas do rio se dá em menor velocidade, como nos seus meandros, e na confluência do Poti com o Parnaíba, onde o material depositado barra as águas do Poti.

\section{VULNERABILIDADE ÀS INUNDAÇÕES EM TERESINA E AS AÇÕES DO PODER PÚBLICO}

\section{A população vulnerável: condições socioeconômicas.}

O Ministério da Integração Nacional e a Companhia de Pesquisa de Recursos Minerais (CPRM), fazendo uma análise sobre a ocorrência e recorrência de desastres nos municípios brasileiros, a saber, deslizamentos e inundações, apontou que Teresina tem sofrido com a ocorrência constante de inundação, solapamento e deslizamento durante episódios de intensas precipitações. Os dados preliminares da CPRM, resultante da pesquisa intitulada "Ação Emergencial para Reconhecimento de Áreas de Alto e Muito Alto Risco a Movimentos de Massas e Enchentes", constataram que existem em Teresina 38 setores de risco, os quais abrigam um total de 5.995 edificações (BRASIL, 2012b).

Os 38 setores indicados pelo Serviço Geológico, a partir das análises promovidas pela empresa especializada e contratada pelo Ministério da Integração Nacional desdobraram-se em 430 subsetores que abrangem 2,86 km² e abrigam, no total, 6.376 edificações e uma população de aproximadamente 28 mil habitantes. Desses 38 setores de riscos a desastres apontados em Teresina, 32 predominam a ocorrência de inundações, em cinco deslizamentos e, em outro, inundação e solapamento de margens dos cursos d'água. Desses, 22 setores estão concentrados na zona centro/norte; oito na zona leste e quatro nas zonas sul e sudeste de Teresina.

A Organização Pan-Americana da Saúde (2014), acerca da vulnerabilidade, destaca que os processos sociais resultam na precariedade das condições de vida e proteção social, incluindo trabalho, renda, saúde, educação, bem como aspectos ligados à infraestrutura, como 
habitações saudáveis e seguras, saneamento, entre outros, que tornam determinados grupos populacionais, como crianças e idosos, principalmente entre os mais pobres, os mais vulneráveis aos desastres. Portanto, para estudos de vulnerabilidade é essencial que sejam feitas análises das condições socioeconômicas da população afetada.

No tocante à renda mensal do domicílio, a pesquisa demonstrou que 56,1\% dos chefes de família das áreas de risco à inundação, contam com até 1 salário mínimo, 35,3\%, entre 2 a 5 salários mínimos e $8,1 \%$ se declararam como sem rendimentos, conforme pode ser visto na figura 6. Percebe-se, portanto, a predominância do baixo rendimento médio mensal da população afetada pelas inundações.

\section{Figura 6: Rendimento médio mensal dos domicílios localizados em áreas de risco de inundação.}

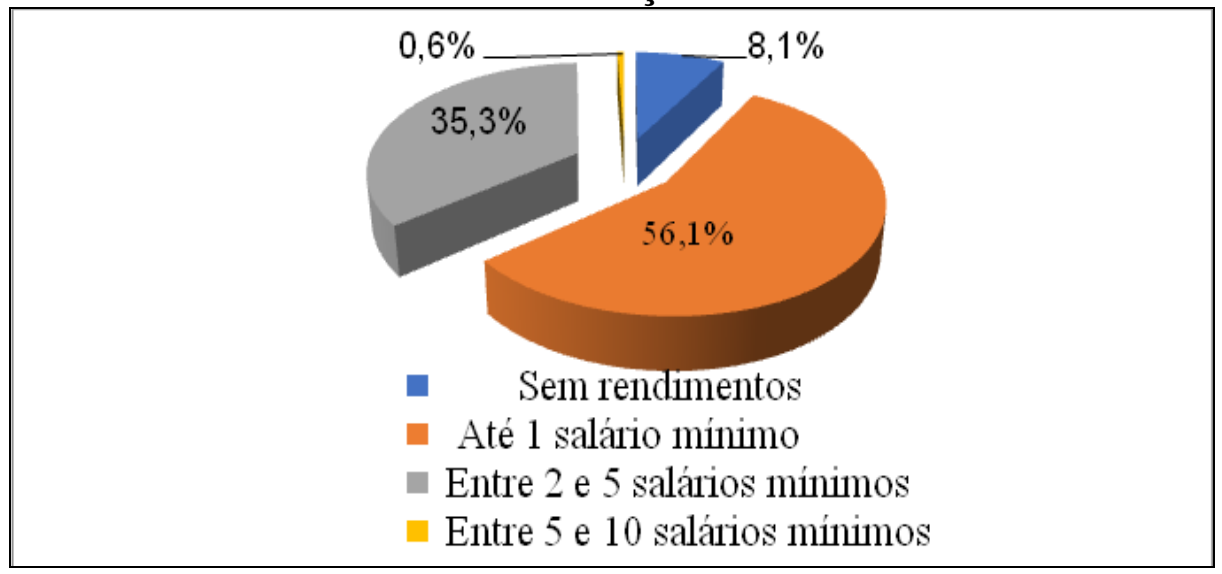

Fonte: Pesquisa Direta (Maio/2015)

Quanto à ocupação e fonte dos rendimentos dos chefes de família, observou-se que $38,3 \%$ são autônomos, 21,1\% possuem emprego regularizado (carteira assinada), 18,1\% são aposentados, 8,1\% são funcionários públicos, seguidos de prestadores de serviços $(5,3 \%)$, recebem bolsas assistencialistas $(1,9 \%)$ e outras fontes de rendimentos $(7,2 \%)$.

Sobre as condições financeiras, Cutter (2011) assinala que se a população residente for rica, com recursos consideráveis para a preparação e resposta a desastres, a comunidade será capaz de se recuperar rapidamente. Caso ela apresente características sociais diferentes, demorará mais tempo para se recuperar, uma vez que a capacidade dos seus habitantes para absorver perdas é limitada. Tal pensamento também se aplica à escolaridade, dado que, baixos níveis de escolaridade podem implicar maiores dificuldades de prevenção e resposta a desastres e, até mesmo, no impedimento de mudança do local em risco, caso necessário. 
A respeito da escolaridade do chefe da família (figura 7), foi constatado que $39 \%$ possuem o ensino fundamental incompleto, 20,3\%, o ensino médio completo, $13,4 \%$ são analfabetos e $12 \%$ concluíram o ensino fundamental. Entre os autônomos, condição trabalhista predominante entre os chefes de família, 40,6\% possuem ensino fundamental completo, 19,6\%, o ensino médio completo e $13 \%$, o ensino fundamental completo. Dentre os que possuem emprego regularizado, 31,6\% não concluíram o ensino fundamental, 30,3\% findaram o ensino médio e apenas 5,3\% terminaram o ensino superior. Já entre os (as) aposentados (as), 48,4\% possuem apenas o fundamental incompleto e 35,9\% são analfabetos (as).

Figura 7: Nível de escolaridade dos chefes de família dos domicílios localizados em áreas de risco de inundação.

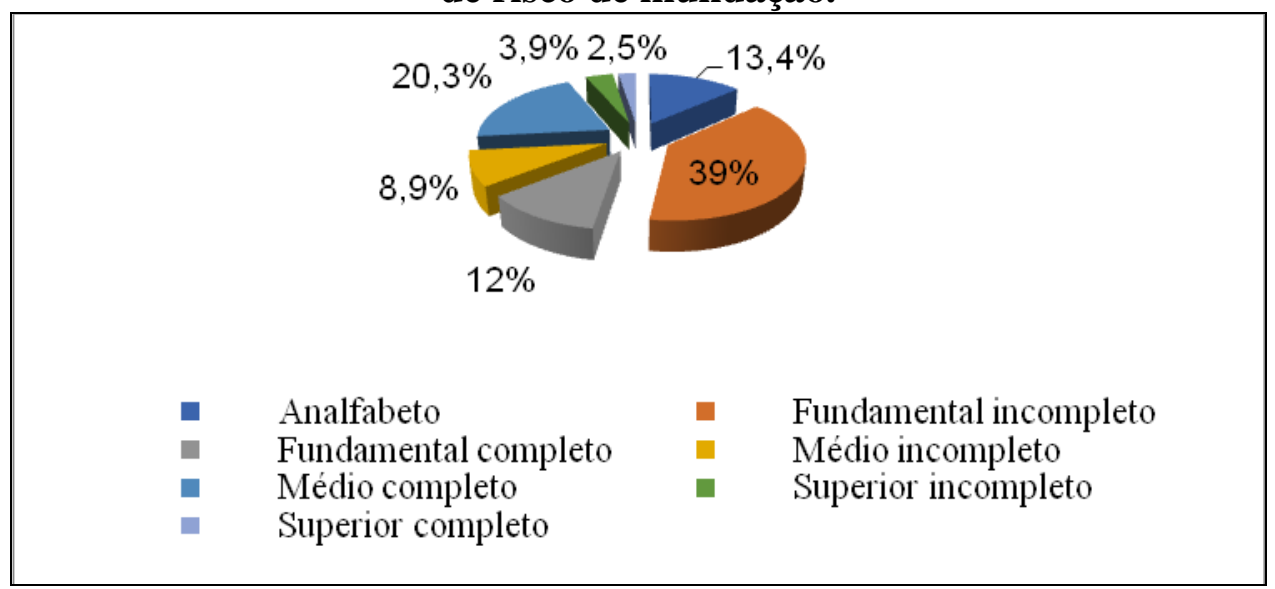

Fonte: Pesquisa Direta (Maio/2015)

Entre os que têm ensino fundamental incompleto estão também 85,7\% dos que declararam receber bolsa assistencialista. Por outro lado, entreos que têm o ensino médio completo se enquadram $30,3 \%$ dos registrados e $37,9 \%$ dos funcionários públicos. Portanto, pode-se afirmar que a baixa escolaridade dos chefes de família que residem nas áreas de risco de inundação se reflete nos seus rendimentos, cerceando, dessa forma, a capacidade de resposta deles à materialização do evento. Ademais, percebeu-se que pessoas analfabetas e com o ensino fundamentalincompleto totalizam $53,6 \%$ da amostra e, entre elas, estão $84,3 \%$ dos aposentados, indicando que são pessoas com idade avançada. Pessoasidosas, com nenhum ou pouco estudo e aposentadas, comrendimentos de um salário mínimo, são vulneráveis às (inundações) e possuem capacidade limitada para buscar outro local a fim de fixar sua moradia 
A densidade domiciliar permite inferirsobre a qualidade de vida diante dos rendimentos auferidos e da quantidade de pessoas em risco de ser afetadas com inundação. Constatou-se que 47,2\% dos domicílios abrigam entre 2 e 4 pessoas, 22,2\% entre 4 e 6 pessoas, 16,9\% contam com até 2 pessoas e 13,6\% abrigam um total acima de 6 pessoas. Dentre os domicílios que têm acima de 6 pessoas, 44,9\% contam com rendimento mensal de até 1 salário mínimo. Nos domicílios onde residem de 4 a 6 pessoas, o rendimento de até 1 salário mínimo sobe para $60 \%$. Cabe destacar também que predomina o rendimento mensal de apenas 1 salário mínimo em 67,2\% dos domicílios com até 2 pessoas e em 53,5\% daqueles que possuem entre 2 e 4 pessoas.

\section{Presença do poder público e ações durante os episódios de inundação}

As ações do poder público são essenciais antes, durante e depois da ocorrência de episódios de inundação. No entanto, tais ações, quando ocorrem em Teresina, são insatisfatórias e ineficientes. Prefeitura, Defesa Civil e Corpo de bombeiros, que são as instituições atuantes durante a ocorrência das inundações, tem se mostrado incipientes, atuando basicamente sobre as consequências dos eventos de modo paliativo.

Segundo a Organização Pan-Americana da Saúde (2014), podem ser citadas como consequências das inundações a interrupção total ou parcial de pontes, ruas e estradas; rompimentos de diques de contenção; interrupção total ou parcial do funcionamento de escolas, comércio, serviços de saúde, entre outros; prejuízos econômicos pela destruição total ou parcial de propriedades, casas e construções, bem como a destruição total ou parcial das fontes de renda e trabalho; perdas de bens materiais e sentimentais; interrupção total ou parcial do fornecimento de serviços de água, eletricidade, gás, transporte e comunicação; dentre outras consequências.

Os questionamentos acerca das ações do poder público durante a ocorrência das inundações, apontaram que apenas $21,7 \%$ dos afetados pelas inundações em Teresina receberam assistência de algum órgão público durante a ocorrência de inundações, enquanto 78,3\% responderam que nunca receberam nenhum tipo de assistência, o que demonstra a ineficiência dos mesmos. Os órgãos que deram assistência a essas famílias, segundo os próprios residentes, foram, principalmente, a Prefeitura (84,5\%), o Corpo de Bombeiro $(8,3 \%)$ e a Defesa Civil $(5,1 \%)$. Tais dados revelam que as ações do poder público abrangeram até hoje um pequeno número de domicílios e tem a Prefeitura como o órgão mais atuante, bem 
mais que a própria Defesa Civil, que deveria ser o órgão mais ativo durante a ocorrência das inundações.

Dentre os que foram contemplados com alguma ação do poder público, como mostra a figura $8,40,7 \%$ responderam que receberam atendimento emergencial, 32,2\% participaram do projeto Família Solidária da Prefeitura e $22 \%$ foram contemplados com a reconstrução ou melhoria habitacional após a ocorrência da inundação.

\section{Figura 8: Ações do poder público nos domicílios atingidos por inundações}

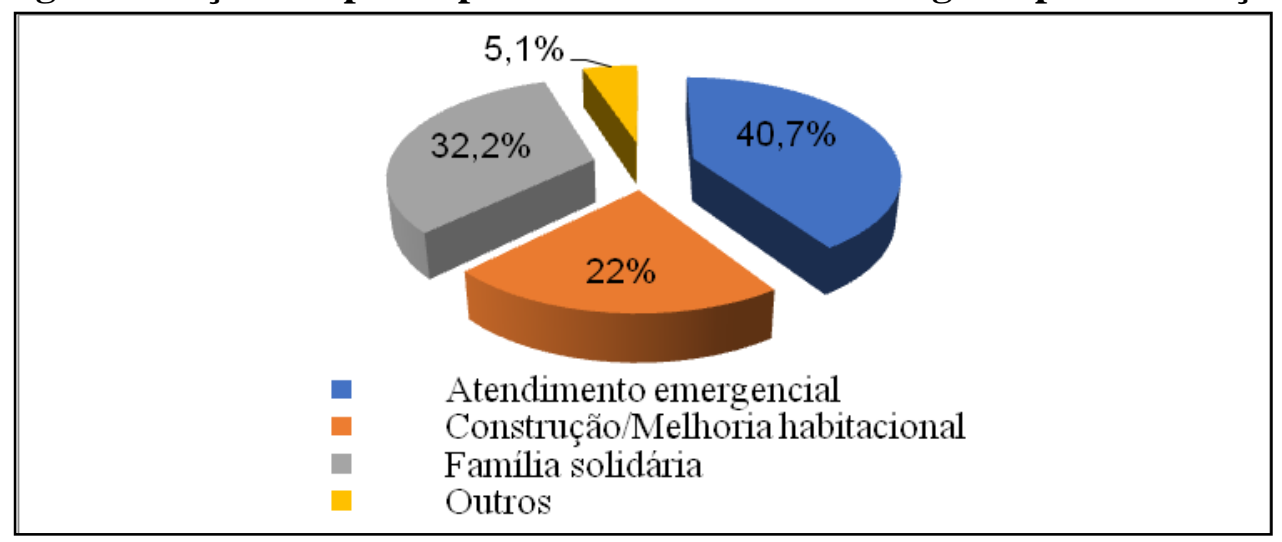

Fonte: Pesquisa Direta (Maio/2015)

Família Solidária é um dos instrumentos que fazem parte do Projeto Cidade Solidária executado pelo poder público municipal e é acionado quando alguma família é removida de uma área de risco, instalando-se na casa de algum parente ou amigo. Nestas ocasiões a Prefeitura custeia a presença dessa família através do repasse de $R \$ 180,00$, mensalmente, durando o tempo necessário à dissipação do risco.

Quanto à presença de postos de saúde e escolas públicas, a pesquisa apontou que em todas as zonas da cidade, os serviços estão presentes. Apenas $14 \%$ dos domicílios das zonas centro/norte e leste e $8,4 \%$ dos domicílios da zona centro/norte não contam, respectivamente, com postos de saúde e escolas públicas em áreas próximas aos setores de risco.

Durante o período chuvoso, nessas áreas de risco à inundação, foram constatadas ocorrências de avarias nos domicílios, perdas de alimentos e de objetos, sendo esses assinalados em menor proporção. Avarias foram apontadas em 24,6\% dos imóveis da zona centro/norte, $17,1 \%$ da zona leste e em $13,3 \%$ da zona sudeste. Perdas de alimentos e objetos ocorreram em 19,5\% dos domicílios da zona leste, $11,6 \%$ da zona centro/norte e em $6,7 \%$ da zona sudeste. 


\section{CONSIDERAÇÕES FINAIS}

Dados acerca de inundações no mundo revelam que há uma tendência global para o crescimento do número de pessoas expostas e afetadas por esse tipo de evento. Esse número pode elevar-se para além de 102 milhões de pessoas por ano. Os mais expostos e o maior número de óbitos estão concentrados em países com baixa renda per capita (ORGANIZAÇÃO PAN-AMERICANA DA SAÚDE, 2014). O Brasil, segundo o EM-DAT, é classificado como um dos países mais afetados por inundações, com mais de 60 desastres cadastrados no período de 1974 a 2003. Segundo o relatório do CRED, em 2008 o Brasil ficou em $10^{\circ}$ lugar entre os países do mundo com maior número de vítimas relacionadas aos desastres naturais, com destaque para os hidrológicos, aqueles que englobam inundações e movimentos de massa, que afetaram 1,8 milhão de pessoas (AMARAL e RIBEIRO, 2009).

A ocupação de áreas inundáveis por populações de baixa renda, com moradias precárias e quase nenhuma infraestrutura urbana é o cenário mais comum das áreas de risco deste tipo de desastre. Em muitos municípios brasileiros, este é o cenário que abriga a população mais vulnerável às inundações e em Teresina, capital do estado do Piauí, tal fato não é diferente. Características do seu sítio urbano, somadas às chuvas intensas e rápidas, são fatores a ser ressaltados para a constante recorrência das inundações e alagamentos em determinados setores da cidade. O crescimento populacional de Teresina, ao longo dos anos e a consequente pressão demográfica por moradia impeliram uma parcela dos teresinenses a ocupar as áreas inundáveis presentes na cidade, aumentando o número de atingidos por inundações.

O Projeto Lagoas do Norte (PLN) consiste na ação mais importante por parte do poder público para solucionar a ocorrência das inundações e reduzir o número de afetados em Teresina. O PLN consiste num conjunto de ações integradas, inter-relacionadas e tecnicamente planejadas, que buscam contribuir para o desenvolvimento sustentável da zona norte da cidade através da requalificação urbana e ambiental. No entanto, o PLN se restringe a alguns bairros localizados no norte da cidade, desprezando o fato de que em outras zonas também ocorrem inundações, embora com menor número de afetados.

A zona norte de Teresina comporta áreas de planície aluvial sujeitas à inundação lenta e gradual, em perímetros de lagoas ou ao longo dos rios Parnaíba e Poti e de seus pequenos tributários inseridos em área totalmente urbanizada. Isto ainda é agravado pelo esgotamento sanitário em céu aberto em todos os setores, pela presença de grande volume de resíduos 
sólidos, que causam a obstrução do sistema de drenagem, provocando alagamentos, por sistemas de drenagens deficientes (presença de diques, porém, sem sistema de bombeamento), pelas cotas das ruas e casas, muito próximas da cota de lâmina d’água e pela presença de algumas casas de taipa construídas sobre solos e sedimentos não consistentes.

Sugere-se, como possível solução para a redução da vulnerabilidade, remoção dos imóveis das áreas mais próximas aos corpos hídricos, bem como melhorias habitacionais naquelas cujas estruturas se encontram bastante precárias. Urge também a necessidade de um planejamento urbano das áreas de expansão da cidade, já que surgem, a cada dia, novos loteamentos, vilas e bairros, que desprezam a topografia local e são desprovidos de sistemas de drenagem que evitem os alagamentos.

\section{Referências}

AMARAL, R. do; RIBEIRO, R.R. Inundações e enchentes. In.: TOMINAGA, L.K;

UNITED NATIONS INTERNATIONAL STRATEGY FOR DISASTER REDUCTION (UNISDR).Terminologyondisastersriskreduction, 2009. Disponível em: http://www.unisdr.org/files/7817_UNISDRTerminologySpanish.pdf Acesso em: 13 de dez. de 2013.

ADIKARI, Y; YOSHITANI, J. Global trends in water-related disasters: an insight for policy makers. The United Nations World Water Assessment Programe. International Centre for Water Hazard and Risk Management (ICHARM). United Nations Educational. Scientific and Cultural Organization. France, 2009.

ALCÂNTARA-AYALA, J. Geomorphology, natural hazards, vulnerability and prevention of natural disasters countries. Geomorphology, v. 47, n 2-4, out., 2002.

BARBOSA, K. Aumenta o número de desabrigados em Teresina. Portal Cabeça de Cuia. 2008. Disponível em: http://www.cabecadecuia.com/teresina/20831/aumenta-o-numero-dedesabrigados-em-teresina- Acesso em 16 mar 2015.

BRASIL. Ministério da Integração Nacional. Defesa Civil. Plano Nacional de Gestão de Riscos e Respostas á Desastres. Fundação Getúlio Vargas, Rio de Janeiro, 2012a.

Ministério de Minas e Energia. Secretaria de Geologia, Mineração e Transformação Mineral. CPRM. Serviço Geológico do Brasil. Ação Emergencial para Reconhecimento de Áreas de Alto e Muito Alto Risco a Movimentos de Massas e Enchentes. Teresina, Piauí. Maio/2012b.

BERTONE, P; MARINHO, C. Gestão de riscos e respostas a Desastres Naturais: a visão do planejamento. In.: VI CONGRESSO DE GESTÃO PÚBLICA - CONSAD, , 2013, Brasília. Anais... Disponível em: http://repositorio.fjp.mg.gov.br/consad/bitstream/123456789/966/1/C6_TP_GEST\%C3\%83O \%20DE\%20RISCOS\%20E\%20RESPOSTA.pdf. Acesso em: 13 denov. de 2013. 
CHAVES, R. J. Ferreira. Teresina - Subsídios para a história do Piauí. Teresina, 1992.

CHAVES, Monsenhor. Como nasceu Teresina. Obras completas, FCMC, 1998, p.163.

CHAVES, S.V.V. A vulnerabilidade socioambiental em Teresina, Piauí. Dissertação (Mestrado em Desenvolvimento e Meio Ambiente). Programa de Desenvolvimento e Meio Ambiente da UFPI. Teresina, 2009.

COELHO, L. Chuvas fazem Teresina decretar estado de emergência. Estadão. Caderno Geral. Abril/2008. Disponível em: http://www.estadao.com.br/noticias/geral,chuvas-fazemteresina-decretar-estado-de-emergencia,150692 Acesso em 16 de mar 2015.

COUTINHO, R. 1926: a maior enchente da história de Teresina ? Portal Piracuruca. 2014. Disponível em: http://www.piracuruca.com/index.php/historia/211-1926-a-maior-enchenteda-historia-de-teresina Acesso em 13 mar 2015.

CUNHA, J.M.P. da. Um sentido para a vulnerabilidade sociodemográfica nas metrópoles paulistas. Revista Brasileira de Estudos Populacionais. Campinas, v.21, n.2, p. 343-347, jul/dez, 2004.

CUTTER, S.L. A ciência da vulnerabilidade: modelos, métodos e indicadores. Revista Crítica de Ciências Sociais, 93, pp. 59-69, junho, 2011

GUHA-SAPIR, D. Disaster Data: a balanced perspective. Catholic University of Louvain. Centre for research on the epidemiology of Disasters (CRED) CRUNCH/USAID). Brussel (Belgium) Issue $\mathrm{n}^{\mathbf{0}}$ 31, march, 2013.

KOBIYAMA, M. et al. Prevenção de desastres naturais: conceitos básicos. Curitiba: Ed. Organic Trading, 2006.

LIMA, I.M.de M.F. O relevo de Teresina, Piauí: compartimentação e dinâmica atual. In.: IX ENCONTRO NACIONAL DA ASSOCIAÇÃO DE PÓS-GRADUAÇÃO E PESQUISA EM GEOGRAFIA, Anais... Goiás, 2011.

Teresina: o relevo, os rios e a cidade. Revista Equador, vol.05, n03 (Edição Especial 2, Teresina, PI, 2016, p.357-397.

LIMA, M.G. de; FERNANDES, R.J.A.R. Análise da ocorrência de eventos extremos no Piauí. Secretaria de Meio Ambiente e Recursos Hídricos do Piauí. s/a.

MAFRA, C.Q.T.; MAZZOLA, M. As razões dos desastres em território brasileiro. In.: SANTOS, R.F. dos. (Org.). Vulnerabilidade ambiental: desastres naturais ou fenômenos induzidos? Brasília: MMA, 2007.

MARCELINO, E.V. Desastres Naturais e Geotecnologias: conceitos básicos. Instituto Nacional de Pesquisas Espaciais (INPE). São José dos Campos, 2008.

Desastres Naturais: conceitos básicos. Instituto Nacional de Pesquisas Espaciais (INPE). Santa Maria, 2007.

MENDONÇA, F. Riscos e vulnerabilidade socioambientais urbanos a contingência climática. Mercator. Vol.9, número especial (1), dez. 2010.

Sociedade e Território - Natal. Vol. 29, N. 2, p. 175-197, Jul./Dez. de 2017. 
Riscos, vulnerabilidade e abordagem socioambiental urbana: uma reflexão a partir da RMC e de Curitiba. Revista Desenvolvimento e Meio Ambiente, n.10, jul-dez, Editora UFPR, 2004, p.139-148.

MOREIRA, Amélia A N. A cidade de Teresina. In: Boletim Geográfico. Rio de Janeiro: IBGE, n. 230, set./out. 1972.

ORGANIZAÇÃO PAN-AMERICANA DA SAÚDE. Desastres Naturais e Saúde no Brasil. Brasília, DF: OPAS, Ministério da Saúde, 2014.

PEDUZZI, P; DAO, H; HEROLD, C. Mapingdisastrous, natural hazardsusing global datasets. Natural Hazards, v. 35, p. 265-289, 2005.

PROGRAMA DAS NAÇÕES UNIDAS PARA O MEIO AMBIENTE (PNUMA). Estado do Meio Ambiente e Retrospectivas Políticas: 1972-2002. In. IBAMA - Instituto Brasileiro do Meio Ambiente e dos Recursos Naturais Renováveis; PNUMA - Programa das Nações Unidas para o Meio Ambiente; UMA - Universidade Livre da Mata Atlântica. Perspectivas do Meio Ambiente Mundial - GEO3. 2004. Disponível em:http://www.wwiuma.org.br/geo_mundial_arquivos/capa_pretexto.pdf Acesso em: 22 de nov. de 2013.

REIS FILHO, A. A. dos. Análise integrada por geoprocessamento da expansão urbana de Teresina com base no Estatuto da Cidade: estudo de potencialidades, restrições e conflitos de interesse. Doutorado (Tese). Programa de Pós-Graduação do Departamento de Geografia da Universidade Federal de Minas Gerais. UFMG, 2012.

ROMERO, G; MASKREY, A. Como entender los desastres naturales. Los desastres non sonnaturales. Red de EstudiosSociales em Prevencion de Desastres em América Latina - LA RED, 1993.

SANTORO, J; AMARAL, R. do. (Orgs.) Desastres naturais: conhecer para prevenir. São Paulo: Instituto Geológico, 2009.

SOBRAL, André; et al. Desastres Naturais - Sistemas de informação e vigilância: uma revisão de literatura. Epidemiologia e Serviços de Saúde. Brasília, n. 19, vol.4, out-dez, 2010, p. 389-402.

TERESINA. Secretaria Municipal de Planejamento e Coordenação Geral. Teresina: aspectos e características - Perfil 1993.

Prefeitura Municipal. Secretaria Municipal de Planejamento e Coordenação Geral. Teresina Agenda 2015 - Plano de Desenvolvimento Sustentável. Teresina, 2002a.

Secretaria Municipal de Planejamento e Coordenação Geral. Teresina Agenda 2015 - Plano de Desenvolvimento Sustentável. Diagnósticos e Cenários. Habitação. Teresina, $2002 b$.

Secretaria Municipal de Planejamento e Coordenação Geral. Teresina 2000 á 2010. Agenda 2030. - Avançando para o futuro: diagnósticos, avanços e desafios. 2013. 67p.

Sociedade e Território - Natal. Vol. 29, N. 2, p. 175-197, Jul./Dez. de 2017. 
Secretaria Municipal de Planejamento e Coordenação Geral. Teresina Agenda 2015 - Plano de Desenvolvimento Sustentável. Diagnósticos e Cenários. Habitação. Teresina, 2002.

Secretaria Municipal de Planejamento e Coordenação Geral. Programa Lagoas do Norte: Relatório de Avaliação Ambiental (RAA). 2006.

Secretaria Municipal de Planejamento e Coordenação Geral. Plano Diretor de Drenagem Urbana de Teresina. Relatório Final, 2010.

UNITED NATIONS DEVELOPMENT PROGRAMME (UNDP). Disaster profiles of the least developed countries. United nations conference on least developed countries.Geneve, 2001. Disponívelem: http://www.un.org/en/development/devagenda/ldc.shtml. Acessoem: 23 de nov. de 2013.

Recebido em Julho de 2017

Aprovado em Dezembro de 2017

Publicado em Dezembro de 2017

Sociedade e Território - Natal. Vol. 29, N. 2, p. 175-197, Jul./Dez. de 2017. 